\title{
Influence of cancer histology on the success of fine needle aspiration of the breast
}

\author{
J LAMB, T J ANDERSON \\ From the Department of Pathology, University of Edinburgh, Scotland
}

SUMMARY Fine needle aspiration (FNA) cytology carried out on 1318 primary breast cancers from 1980 to 1986 inclusive showed that 198 were well recognised, histological special types. These included medullary, mucoid, tubular, cribriform and lobular invasive cancers, and non-invasive cancers. Excluding these special histological types, the overall number successfully identified (malignant plus suspicious) by fine needle aspiration was $940(84 \%)$, although in only $820(73 \%)$ was malignancy definitely diagnosed. The results for the special types were variable, the mucoid and medullary cancers being consistently identified while the other types were not. For tubular and cribriform, lobular and non-invasive ductal cancers a malignant diagnosis was made in $30 \%$ to $40 \%$ of cases, although inclusion of suspicious results gave identification figures of $60 \%$ to $70 \%$.

Particular cytological patterns are characteristic of some special histological cancer types but lesion cellularity, size, and physical definition are all intrinsic factors influencing success of FNA diagnosis. About $10 \%$ of all primary breast cancers seem to have certain histological properties which further reduce the success of fine needle aspiration.

The main factors influencing the success of FNA of the breast have already been reported..$^{1-3}$ These include the aptitude of the aspirator, the experience of the cytopathologist, and the size and palpability of the lesion as the major variables. The tendency of cancers detected by screening to be well differentiated or of special histological type $\mathrm{A}^{4}$ prompted an analysis of the effect of histological type on the results of fine needle aspiration. This seemed to be particularly relevant in view of the recommendation that fine needle aspiration cytology is incorporated in the assessment of abnormalities detected by screening. ${ }^{5}$

\section{Material and methods}

The fine needle aspiration cytology specimens were received in the pathology department of the University of Edinburgh between 1980 and 1986 inclusive. They came from 1318 primary breast cancers, subsequently confirmed histologically. Most of these occurred in symptomatic patients but about $12 \%$ were referred from the Edinburgh Breast Screening Project. ${ }^{6}$

Pathology findings in the biopsy specimens were extracted from the pathology register maintained for

Accepted for publication 2 February 1989 the Edinburgh Breast Screening Project ${ }^{6}$ which recorded all cancers detected by symptoms and at presentation by screening. The size of any invasive cancer was the maximum diameter of the lesion measured macroscopically in the biopsy specimen. Non-invasive cancers were not routinely measured but the extent was subsequently judged from the slides or specimen $x$-ray picture. The histological type of each cancer was recorded in the register and those of special histological type ${ }^{7}$ were reviewed.

The aspirates were obtained processed and assessed as previously described..$^{18}$ In 1982,1983 , and 1985 an assigned aspirator performed most of the aspirates. ${ }^{2}$ With few exceptions the cytology was reported by the same two cytopathologists (JL and TJA) and details of the results were obtained from the aforementioned pathology register. There were four principal categories of reporting issued as previously described ${ }^{3}$ : (i) positive unequivocal malignant cells present; (ii) suspicious - equivocal cells (probably or possibly malignant) present; (iii) benign-negative for malignant characteristics; and (iv) acellular-inadequate specimen lacking parenchymal cells.

\section{Results}

Over the seven years studied fine needle aspiration cytology specimens were obtained from 1318 primary 
Table 1 Special histological cancer types

\begin{tabular}{ll}
\hline Common & Uncommon \\
\hline Lobular & Papillary \\
Mucoid & Signet ring cell \\
Medullary & Spindle cell \\
Tubular & Squamous \\
Cribriform & \\
Non-invasive & \\
\hline
\end{tabular}

cancers, which were subsequently confirmed histologically. Of these, $1120(85 \%)$ were of no special histological type and $198(15 \%)$ were of special histological type. Special histological types in this group are listed in table 1: the most common invasive ones being lobular, tubular and cribriform, mucoid, and medullary. The results of fine needle aspiration are shown in table 2; the numbers and percentages in each of the four categories of cytological report are given for each cancer group. A few of the special types of cancer listed in table 1 were too rare to be identified separately and are grouped together in one column.

The overall percentage (table 2) of positive (diagnostic) aspirates for the cancers of no special type was $73.2 \%$; positive plus suspicious (identifying women most likely to have cancer) $83.9 \%$. The mucoid cancers were $92.4 \%$ positive, positive plus suspicious $96 \%$; the medullary cancers were $75 \%$ and $100 \%$, respectively. In contrast, the other special cancer types gave much lower percentages of positive reports ranging from $29 \cdot 7 \%$ to $46 \cdot 2 \%$. Worth noting was the increased proportion of suspicious reports in all special types of cancer, except mucoid, compared with those of no special type. The percentage of acellular reports was particularly high in the lobular invasive cancers: $(27.8 \%)$ and in the non-invasive ductal cancers $(21.6 \%)$. Of the 37 non-invasive ductal cancers, 13 were found only on microscopical examination. If these 13 cases of microscopical "chance" findings on histology are excluded the results of the non-invasive cancers showed an improvement from $30 \%$ up to $46 \%$ positive and from $60 \%$ up to $80 \%$ positive plus suspicious. Of the macroscopic non-invasive ductal cancers, four were multifocal lesions affecting all four

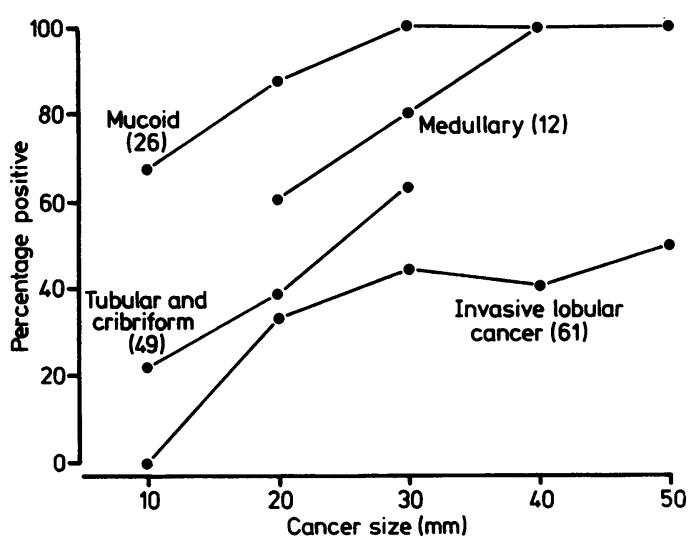

Figure Percentage of cancers reported as positive on cytology arranged according to lesion size for four special types of invasive cancer. Lesion size was measured macroscopically on excised tissue.

quadrants of the breast, the others ranged in size from $3 \mathrm{~mm}$ to $30 \mathrm{~mm}$. Certain groups of cancer noted above and comprising $160(12.2 \%)$ of this series were therefore difficult to diagnose or identify by fine needle aspiration cytology.

The figure shows the correlation between the percentage of positive cytology reports and the sizes of the four principal special types of invasive cancer. All four types of invasive cancer showed an improvement in the percentage of positive results with increasing size. The levels of improvement differed, however, and notably the lobular group changed little above $20 \mathrm{~mm}$ in size.

\section{Discussion}

To appreciate fully the use of fine needle aspiration cytology in the management of breast diseases an awareness of the major influencing variables is important. This study has shown that histological type must be considered, along with lesion size, palpability, the

Table 2 Cytology results for primary cancers (1980-86) according to histological type

\begin{tabular}{|c|c|c|c|c|c|c|c|c|}
\hline \multirow[b]{2}{*}{ Cytology } & \multicolumn{8}{|c|}{ Types of cancer } \\
\hline & $\begin{array}{l}\text { Cancer of no } \\
\text { special type }\end{array}$ & Mucoid & Medullary & $\begin{array}{l}\text { Tubular and } \\
\text { cribriform }\end{array}$ & $\begin{array}{l}\text { Invasive } \\
\text { lobular } \\
\text { cancer }\end{array}$ & $\begin{array}{l}\text { Non-invasive } \\
\text { cancer of } \\
\text { ductal type }\end{array}$ & $\begin{array}{l}\text { Cancers of } \\
\text { special type } \\
\text { not already } \\
\text { included }\end{array}$ & Total \\
\hline $\begin{array}{l}\text { Positive (\%) } \\
\text { Suspicious (\%) } \\
\text { Benign (\%) } \\
\text { Acellular (\%) } \\
\text { Total }\end{array}$ & $\begin{array}{r}820(73.2) \\
120(10.7) \\
66(5.9) \\
114(10 \cdot 2) \\
1120\end{array}$ & $\begin{array}{rr}24 & (92 \cdot 4) \\
1 & (3 \cdot 8) \\
1 & (3 \cdot 8) \\
26 & \end{array}$ & $\begin{array}{l}9(75) \\
3 \text { (25) } \\
\overline{-} \\
12\end{array}$ & $\begin{aligned} 21 & (42.9) \\
13 & (26 \cdot 5) \\
9 & (18.4) \\
6 & (12 \cdot 2) \\
49 & \end{aligned}$ & $\begin{array}{rr}21 & (34 \cdot 4) \\
16 & (26 \cdot 3) \\
7 & (11 \cdot 5) \\
17 & (27 \cdot 8) \\
61 & \end{array}$ & $\begin{array}{r}11(29 \cdot 7) \\
11(29 \cdot 7) \\
7(19 \cdot 0) \\
8(21 \cdot 6) \\
37\end{array}$ & $\begin{array}{rr}6 & (46 \cdot 2) \\
4 & (30 \cdot 7) \\
2 & (15 \cdot 4) \\
1 & (7 \cdot 7) \\
13 & \end{array}$ & $\begin{array}{r}912 \\
168 \\
92 \\
146 \\
1318\end{array}$ \\
\hline
\end{tabular}


cytopathologist's experience and the aspirator aptitude. There are few reports, however, which address the variation of results according to histological appearance. Eisenberg et al reported a high diagnostic success $(84 \%)$ with medullary cancers similar to our experience, but they were less successful (58\%) with mucoid cancers. ${ }^{9}$ The low success $(34.4 \%)$ that we obtained in malignant diagnosis for lobular invasive cancer was also similar to the $25 \%$ reported by Eisenberg $e \mathrm{al}^{9}$ and the $29 \%$ recorded by Patel $e t$ $a l^{10}$ Worth noting for this histological type of cancer was the failure to improve beyond $50 \%$ success in malignant diagnoses with increasing lesion size. This must reflect the "target" difficulty imposed by the diffuse growth pattern characterising this cancer type which could also account for the high proportion $(27.8 \%)$ of acellular specimens in this group. Similarly, the likely explanation for the high proportion of benign $(18.4 \%)$ or suspicious $(26.5 \%)$ reports for invasive tubular and cribriform cancers, compared with $5.9 \%$ and $10.2 \%$, respectively, for those cancers of no special type in our series could be explained by difficulty of categorising the small, well differentiated cells of these lesions.

Although the overall results for non-invasive cancers were disappointingly low, it must be emphasised that in a third of these the lesion was of microscopic dimension only and some had required guided needle localisation biopsy for removal.

In a study of FNA cytology of so-called "minimal" cancers which included 19 non-invasive cancers Matsuda et al achieved a malignant diagnosis of $73.7 \%$ in that subset. " The sizes of the lesions were not given but they were stated as being all radiologically or echographically obviously malignant, and this may have contributed to the higher rates of positive diagnoses.

While we recognise that in an individual case the cytological appearance may prompt the reader to consider a particular histological type of cancer this is not the point at issue here. Our analysis is primarily intended to improve awareness of the diversity of factors influencing success. In addition to the factors previously identified, our overall results show that certain histological types of primary breast cancers have inherent properties which militate against the success of fine needle aspiration in the diagnosis of breast cancer. The proportion may vary in different series but it is unlikely to be less than $10 \%$ of cases. This should be borne in mind when using this reliable diagnostic tool in combination with clinical and mammographic information in the diagnosis of breast cancer. This has particular relevance where increased numbers of special histological types of cancers ${ }^{4}$ may be expected as breast screening facilities become more generally available.

This work was funded by grants from the Scottish Home and Health Department and the Cancer Research Campaign.

We acknowledge the cooperation of Professor Forrest, Mr Chetty, and the staff of the breast unit at Longmore Hospital, Edinburgh, and Dr Maureen Roberts (clinical director), and the staff of the Edinburgh Breast Screening Clinic.

We thank Carolyn Williams and Rosemary Williams, who maintained the pathology register and Joyce Garson for secretarial assistance.

\section{References}

1 Dixon JM, Anderson TJ, Lamb J, Nixon SJ, Forrest APM. Fine needle aspiration cytology, in relationships to clinical examination and mammography in the diagnosis of a solid breast mass. Br J Surg 1984;71:593-6.

2 Barrows GH, Anderson TJ, Lamb J, Dixon JM. Fine needle aspiration of breast cancer. Relationship of clinical factors to cytology results in 689 primary malignancies. Cancer 1986; 58:1493-8.

3 Lamb J, Anderson TJ, Dixon MJ, Levack P. Role of fine needle aspiration cytology in breast cancer screening. J Clin Pathol 1987;40:705-9.

4 Anderson TJ, Lamb J, Alexander F, et al. Comparative pathology of prevalent and incident cancers detected by breast screening. Lancet 1986;ii:519-22.

5 Working Group (chairman APM Forrest). Breast cancer screening. Report to the Health Ministers of England, Wales, Scotland and Northern Ireland. London: HM Stationery Office, 1987.

6 Roberts MM, Alexander FE, Anderson T, et al. The Edinburgh randomised trial of screening for breast cancer: Description of method. Br J Cancer 1984;50:1-6.

7 Page DL, Anderson TJ, eds. Diagnostic histopathology of the breast. Edinburgh: Churchill Livingstone, 1988.

8 Dixon JM, Lamb J, Anderson TJ. Fine needle aspiration cytology of solid breast lumps: the importance of the aspiration. Lancet 1983;ii:544.

9 Eisenberg AJ, Hajdu SI, Wilhelmus J, Melamed MR, Kinne D. Preoperative aspiration cytology of breast tumors. Acta Cytol 1986;30:135-46.

10 Patel JJ, Gartell PC, Smallwood JA, et al. Fine needle aspiration cytology of breast masses: an evaluation of its accuracy and reasons for diagnostic failure. Ann Roy Coll Surg England 1987;69:156-9.

11 Matsuda M, Nagumo S, Koyama H, Terasawa T. Fine needle aspiration cytology of "minimal" breast cancer. Acta Cytol 1986;30:501-4.

Requests for reprints to: Dr J Lamb, Department of Pathology, University Medical School, Teviot Place, Edinburgh EH8 9AG, Scotland. 